\title{
Short communication: Occurrence of methicillin-resistant Staphylococcus aureus and coagulase-negative staphylococci in dairy goat herds in Ohio, United States
}

\author{
G. S. Moura, ${ }^{*}$ W. A. Gebreyes, †‡ M. F. S. Marques, ${ }^{*}$ D. T. Stipp, ${ }^{*}$ F. N. Souza,§ L. B. Da Costa, $\dagger$ \\ and C. J. B. Oliveira* $\ddagger^{1}$ \\ *Department of Veterinary Sciences, Federal University of Paraiba, Areia 58397-000, Brazil \\ †Department of Veterinary Preventive Medicine, College of Veterinary Medicine, and \\ ‡Global One Health initiative (GOHi), The Ohio State University, Columbus 43210 \\ §Department of Clinical Science, Faculty of Veterinary Medicine and Animal Science, University of São Paulo, São Paulo 05308-270, Brazil
}

\begin{abstract}
In light of the scarcity of information about the occurrence and epidemiology of methicillin-resistant Staphylococcus aureus (MRSA) and coagulase-negative staphylococci (MRCNS) in small ruminants in general, and particularly dairy goats, we launched this limitedscope study. The findings reported here show the detection of MRSA and MRCNS in goat milk and teat skin samples from dairy goat herds in the state of Ohio. A total of 120 milk samples and 120 teat-swab samples were collected from 5 farms. After conventional isolation and phenotypic characterization of the staphylococci colonies, bacterial isolates were tested by PCR assay targeting the genes nuc to identify Staphylococcus aureus and mecA to detect MRSA and MRCNS. The clonal complexes of MRSA isolates was also determined by multiloccus sequence typing. Fifteen $(6.2 \%)$ positive $S$. aureus samples were found in this study: 9 from milk and 6 from teat skin samples. Four (2\%) MRSA isolates were detected and, using multiloccus sequence typing genotyping, these were designated to clonal complexes CC133 ( $\mathrm{n}=2$; milk samples) and CC5 ( $\mathrm{n}=2$; teat skin). Three (1.25\%) coagulase-negative staphylococci isolates from the teat skin also harbored the mecA gene. Although, the MRSA isolated from milk samples is not a typical human-associated lineage, the CC5 clone isolated from teat skin is a common and widespread clonal complex associated with humans, suggesting that this extramammary niche could be a relevant reservoir of methicillin-resistant staphylococci. Furthermore, the fact that $75 \%$ of MRSA were recovered from 1 farm showing poor hygiene practices strengthens the hypothesis that good hygiene practices could be useful to prevent persistence and spread of MRSA at a farm level.
\end{abstract}

Received June 20, 2017.

Accepted March 24, 2018.

${ }^{1}$ Corresponding author: celso.oliveira@pq.cnpq.br
Key words: livestock-associated methicillin-resistant staphylococci, MLST, dairy goat

\section{Short Communication}

Mastitis is the most costly disease in dairy goat production (Persson and Olofsson, 2011; Zhao et al., 2015). Among mastitis pathogens, CNS are the most common cause of IMI in dairy goats, followed by Staphylococcus aureus (Bergonier et al., 2003; Zhao et al., 2015). The infected mammary gland is the primary reservoir of staphylococci in ruminants; however, it can be isolated from extramammary sites, such as the teat skin, which may contribute to the spread of staphylococci in dairy goat herds (Bergonier et al., 2003; Mørk et al., 2010).

The importance of staphylococci in dairy goat herds is not only limited to animal production, but is also a relevant to public health. For instance, staphylococci resistance to antimicrobial drugs has been observed in several studies (França et al., 2012; Eriksson et al., 2013; Cortimiglia et al., 2015). Likewise, the importance of antimicrobial resistance of Staph. aureus was recently highlighted by the World Health Organization (WHO), as this pathogen is regarded among the priority pathogens that pose the greatest threat to human health in terms of growing global resistance to antimicrobial agents (WHO, 2017). A special public health concern is the potential risk of transmission of methicillin-resistant Staph. aureus (MRSA) and CNS (MRCNS) to humans (van Rijen et al., 2008; Pantosti, 2012; Larsen et al., 2016).

The potential for zoonotic transmission of staphylococci between livestock, companion animals, and humans (van Rijen et al., 2008; Pantosti, 2012; Larsen et al., 2016) has been exemplified by the emergence of MRSA ST398 (Neyra et al., 2014). Thus, accurate and rapid detection and typing of Staph. aureus is crucial to a better understanding of the Staph. aureus epidemiology and control this infectious organism among animal 
production systems. Conversely, scarce information exists about the occurrence of MRSA and MRCNS and their epidemiology in dairy goat herds. To the best of our knowledge, ours is the first report on the detection of MRSA and MRCNS isolated from milk and teat skin samples from US dairy goat herds. Furthermore, MRSA isolates were characterized by a molecular typing method to better understand the implications of the isolates to public health.

Farms were selected based on the Ohio State University database (Infectious Diseases and Molecular Epidemiology Laboratory Database). Farmers were invited to join the study by email, 5 farms agreed to join the experiment, and visits were scheduled. Teat swabs and milk samplings were collected from a random subset of 120 lactating dairy goats during the milking routine procedures on each farm. All farms were located in a radius of 200 miles from Columbus, Ohio, and had Nubian, Toggenburg, and Saanen breeds as base of their herds. Dairy products were the primary activity in 3 of the farms, and 4 of them participated in fairs and expositions. A description of the number of animals sampled, routine milking practices of each farm, and type of parlor is shown in the Table 1.

Teat surface samplings were performed by rubbing a sterile moistened swab onto each teat and transferring them into a sterile tube containing $5 \mathrm{~mL}$ of MüllerHinton broth (BBL Mueller Hinton Broth, Heidelberg, Germany) with $6.5 \% \mathrm{NaCl}$. Afterward, the teat ends were scrubbed with cotton containing $70 \%$ ethanol and composite milk samples from both halves were aseptically collected into $10-\mathrm{mL}$ sterile vials after discarding the first 3 milk streams. One hundred twenty animals were sampled and milk samples were kept under refrigeration conditions for transportation until processing at the laboratory.

Teat swab samples were initially incubated at $37^{\circ} \mathrm{C}$ for $12 \mathrm{~h}$ and then streaked onto mannitol salt agar (MSA; BD, Heidelberg, Germany) and Oxacillin Resistant Screen Agar (BD) in parallel and incubated at $37^{\circ} \mathrm{C}$ for $12 \mathrm{~h}$. Homogeneous colonies that were circular, pinhead, convex with entire margins, and light yellow were selected. These colonies were streaked onto
Müller-Hinton agar plates (BD Mueller Hinton II Agar, Heidelberg, Germany) and incubated for $24 \mathrm{~h}$ at $37^{\circ} \mathrm{C}$ for further identification. Additionally, these colonies were also streaked onto Oxacillin Resistant Screen Agar (BD) and incubated at $37^{\circ} \mathrm{C}$ for $24 \mathrm{~h}$. Growth was identified and results were recorded. Catalase-positive colonies were tested by coagulase production by means of a commercial kit (BBL Coagulase Plasma, BD). For DNA extraction, a commercial kit (Qiagen DNeasy Blood and Tissue kit, Qiagen, Valencia, CA) was used according to the manufacturer's protocol (DNeasy Blood \& Tissue Handbook; https://www.qiagen.com).

Bacterial isolates were tested by PCR assay targeting the genes nuc to identify Staph. aureus and mecA to detect MRSA and MRCNS. Briefly, $1 \mu \mathrm{L}$ of DNA template was added to a $24-\mu \mathrm{L}$ master mix using a commercial kit (Illustra PuReTaq Ready-To-Go PCR beads, GE Healthcare, Little Chalfont, UK) with primer sequences and under PCR conditions listed in Table 2. Electrophoresis of PCR products was performed on 1\% agarose gel stained with ethidium bromide. The DNA fragments were visualized in a UV transilluminator and photographed.

Sequencing analysis of the MRSA isolates was performed regarding 7 housekeeping genes (arcC, aro $E$, $g l p F, g m k, p t a, t p i, y q i L)$, as previously described by Enright et al. (2000). Based on the sequence analysis, multilocus sequence typing (MLST) was determined by analyzing the allelic profiles using the MLST database (http://saureus.mlst.net/) and the identification of sequence types.

Out of 120 teat swabs samples, $53(44 \%)$ and $5(4 \%)$ bacterial isolates were recovered by MSA and oxacillin screen agar, respectively. Among the 120 milk samples, $12(10 \%)$ and $2(2 \%)$ isolates grew in MSA and oxacillin screen agar, respectively. All samples with growth on MSA plates were tested for coagulase and catalase. Among those, 9 samples (14\%) from milk and 6 samples (94\%) from teat skin samples were phenotypically identified as coagulase-positive. Those 15 (64\%) coagulase-positive staphylococci were further confirmed as Staph. aureus by PCR, and $4(2 \%)$ were confirmed as MRSA by testing the mecA gene. Three (1\%) CNS

Table 1. Characteristics of farms enrolled in the study, with description of number of animals sampled per farm, type of milking parlor, and milking routine procedures

\begin{tabular}{lcll}
\hline Farm & $\begin{array}{c}\text { Number of animals } \\
\text { sampled }\end{array}$ & Type of milking parlor & Teat dipping \\
\hline Farm A & 48 & Parallel milking parlor & Not used \\
Farm B & 22 & Manual milking & Pre- and postdipping \\
Farm C & 15 & Milking machine & Pre- and postdipping \\
Farm D & 20 & Milking machine & Pre- and postdipping \\
Farm E & 15 & Manual milking & Postdipping \\
\hline
\end{tabular}


Table 2. Primers and cycling conditions used to identify Staphylococcus aureus and methicillin-resistant staphylococci

\begin{tabular}{|c|c|c|c|c|c|}
\hline Primer & Primer sequence $\left(5^{\prime}-3^{\prime}\right)$ & $\begin{array}{l}\text { Amplicon } \\
\text { size (bp) }\end{array}$ & \multicolumn{3}{|c|}{ PCR conditions } \\
\hline $\begin{array}{l}\text { nuc } 1^{1} \\
\text { nuc } 2^{1}\end{array}$ & $\begin{array}{l}\text { TCAGCAAATGCATCACAAACAG } \\
\text { CGTAAATGCACTTGCTTCAGG }\end{array}$ & 279 & $94^{\circ} \mathrm{C}$ for $1 \mathrm{~min}$ & $55^{\circ} \mathrm{C}$ for $0.5 \mathrm{~min}$ & $72^{\circ} \mathrm{C}$ for $1.5 \mathrm{~min}$ \\
\hline $\begin{array}{l}\text { mecA, forward }{ }^{2} \\
m e c A, \text { reverse }^{2}\end{array}$ & $\begin{array}{l}\text { GGGATCATAGCGTCATTATTC } \\
\text { AACGATTGTGACACGATAGCC }\end{array}$ & 533 & $94^{\circ} \mathrm{C}$ for $3 \mathrm{~min}$ & $50^{\circ} \mathrm{C}$ for $1 \mathrm{~min}$ & $72^{\circ} \mathrm{C}$ for $1 \mathrm{~min}$ \\
\hline
\end{tabular}

${ }^{1}$ Ciftci et al. (2009).

${ }^{2}$ Del Vecchio et al. (1995).

isolates from the teat skin carrying the $m e c A$ gene were also detected. Among the 4 MRSA-positive samples, 3 (75\%) were recovered from farm A and $1(25 \%)$ from farm E. The frequencies of staphylococcal detection are shown in Table 3.

Furthermore, MRSA strains were typed by MLST to determine their clonal complex (CC). Two MRSA were isolated from the milk samples were assigned to CC133 (6-66-46-2-7-50-18), whereas the other 2 originating from the teat skin were assigned to CC5 $(1-4-1-4-12-1-10)$.

To the best of our knowledge, the current study is the first investigating the presence of MRSA and MRCNS in dairy goat herds in the United States. Evidence exists that CC133 Staph. aureus evolved as the result of a human to ruminant host jump followed by adaptive genome diversification (Guinane et al., 2010). Therefore, the MRSA isolates from goat milk in the present study can be considered a ruminant-specific genotype (Guinane et al., 2010; Eriksson et al., 2013; Merz et al., 2016).

On the other hand, the MRSA isolates from teat skin diverge from those isolated from milk samples. Interestingly, teat skin MRSA strains belonged to CC5, which is a common and widespread clonal complex associated with hospital-associated and community-associated MRSA (Rodríguez-Noriega et al., 2010; Monecke et al., 2011). Thus, we hypothesized that the close contact of humans to the teat skin during milking practices favored the colonization of the teat skin with this clonal complex, and may be a relevant reservoir of MRSA. Furthermore, it has been suggested that CC5 clone isolates can carry many virulence-associated genes that may favor its persistence and spread (Monecke et al., 2011)

It has been demonstrated that hygiene measures in dairy goat production are effective in reducing Staph. aureus-associated IMI and thus improving milk quality (Contreras et al., 2007). In the current study, $75 \%$ of the MRSA isolates were detected in farm A. This farm was shown to have poor sanitary practices (i.e., neither pre- nor postdipping usage), which could favor animal health problems such as mastitis. Moreover, all MRCNS were isolated from the teat skin, which have important implications to human health. Several reports suggested the transfer of methicillin resistance of CNS to methicillin-susceptible Staph. aureus (Barbier et al., 2010; Tsubakishita et al., 2010). Considering the findings of our study, milking routine may also influence the persistence of MRSA and MRCNS in the herd and consequently have implications to public health. Although MRSA and MRCNS in milk can be considered a minor food safety issue due to pasteurization, consumption of raw milk or cheese made of unpasteurized milk by the general population, dairy producers, and their families might be an important vehicle of transmission of zoonotic bacteria. Furthermore, the potential role of foods as reservoirs of antimicrobial resistance genes that can

Table 3. Frequencies of Staphylococcus aureus, CNS, methicillin-resistant Staphylococcus aureus (MRSA), and methicillin-resistant CNS (MRCNS) isolated from milk $(\mathrm{n}=120)$ and teat skin (TSK; $\mathrm{n}=120)$ samples based on growth on mannitol salt agar distributed per farm

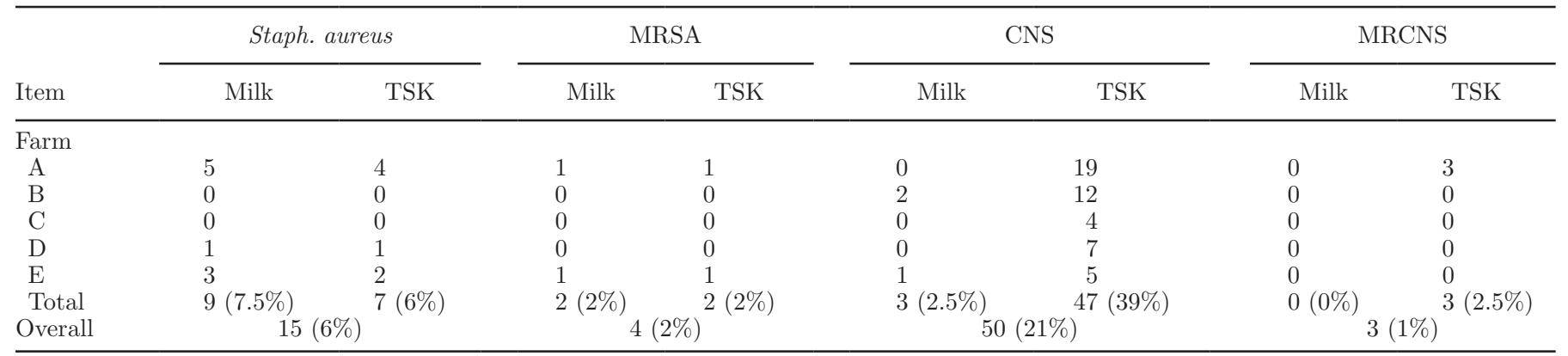


be transferred to other bacteria cannot be neglected. In summary, our study indicates that MRSA belonging to $\mathrm{CC} 133$ can be associated with IMI in goat herds in the United States, and the identification of MRSA CC5 in teat swabs is of special concern considering its relevance to humans. Last, although a limited number of farms were sampled, the fact that most MRSA isolates $(75 \%)$ originated from 1 farm with poor hygiene practices indicates the necessity of understanding potential risk factors for occurrence of MRSA and MRCNS in goat dairy farms. Moreover, further studies are required to investigate the role of MRSA and MRCNS as a cause of contagious subclinical IMI.

\section{ACKNOWLEDGMENTS}

This work was financially supported by The Brazilian National Council of Scientific and Technological Development (CNPq, Brasilia, Brazil; Proc. CsF 200880/2012-8) under the Science Without Borders Program. We also thank the Ohio Dairy Goat Association (Salesville, $\mathrm{OH}$ ) for logistics support and producers for their willingness to participate in this study.

\section{REFERENCES}

Barbier, F., E. Ruppé, D. Hernandez, D. Lebeaux, P. François, B. Felix, A. Desprez, A. Maiga, P. L. Woerther, K. Gaillard, C. Jeanrot, M. Wolff, J. Schrenzel, A. Andremont, and R. Ruimy. 2010. Methicillin-resistant coagulase-negative staphylococci in the community: High homology of SCCmec IVa between Staphyococcus epidermidis and major clones of methicillin-resistant Staphylococcus aureus. J. Infect. Dis. 202:270-281.

Bergonier, D., R. de Crémoux, R. Rupp, G. Lagriffoul, and X. Berthelot. 2003. Mastitis of dairy small ruminants. Vet. Res. 34:689-716.

Ciftci, A., E. E. Onuk, A. Findik, T. Yildirim, and M. U. Sogut. 2009. Molecular typing of Staphylococcus aureus strains from ovine mastitis by pulsed-field gel electrophoresis and polymerase chain reaction based on coagulase and protein A gene polymorphisms. J. Vet. Diagn. Invest. 21:849-853. https://doi.org/10.1177/ 104063870902100614.

Contreras, A., D. Sierra, A. Sánchez, J. C. Corrales, J. C. Marco, M. J. Paape, and C. Gonzalo. 2007. Mastitis in small ruminants. Small Rumin. Res. 68:145-153.

Cortimiglia, C., V. Bianchini, A. Franco, A. Caprioli, A. Battisti, L. Colombo, K. Stradiotto, F. Vezzoli, and M. Luini. 2015. Short communication: prevalence of Staphylococcus aureus and methicillin-resistant $S$. aureus in bulk tank milk from dairy goat farms in Northern Italy. J. Dairy Sci. 98:2307-2311.

Del Vecchio, V. G., J. M. Petroziello, M. J. Gress, F. K. McCleskey, G. P. Melcher, H. K. Crouch, and J. R. Lupski. 1995. Molecular genotyping of methicillin-resistant Staphylococcus aureus via fluorophore-enhanced repetitive-sequence PCR. J. Clin. Microbiol. $33: 2141-2144$.

Enright, M. C., N. P. J. Day, C. E. Davies, S. J. Peacock, and B. G. Spratt. 2000. Multilocus sequence typing for characterization of methicillin-resistant and methicillin-susceptible clones of Staphylococcus aureus. J. Clin. Microbiol. 38:1008-1015.
Eriksson, J., C. Espinosa-Gongora, I. Stamphoj, A. R. Larsen, and L. Guardabassi. 2013. Carriage frequency, diversity and methicillin resistance of Staphylococcus aureus in Danish small ruminants. Vet. Microbiol. 163:110-115.

França, C. A., R. M. Peixoto, M. B. Cavalgante, N. F. Melo, C. J. B. Oliveira, J. A. Veschi, R. A. Mota, and M. M. Costa. 2012. Antimicrobial resistance of Staphylococcus spp. from small ruminant mastitis in Brazil. Pesqui. Vet. Bras. 32:747-753.

Guinane, C. M., N. L. Ben Zakour, M. A. Tormo-Mas, L. A. Weinert, B. V. Lowder, R. A. Cartwright, D. S. Smyth, C. J. Smyth, J. A. Lindsay, K. A. Gould, A. Witney, J. Hinds, J. P. Bollback, A. Rambaut, J. R. Penadés, and J. R. Fitzgerald. 2010. Evolutionary genomics of Staphylococcus aureus reveals insights into origin and molecular basis ruminant host adaptation. Genome Biol. Evol. 2:454-466.

Larsen, J., M. Stegger, P. S. Andersen, A. Petersen, and A. R. Larsen., HWesth, Y., A. Agersø, B. Fetsch, A. Kraushaar, A. T. Käsbohrer, S. Feßler, C. Schwarz, W. Cuny, P. Witte, O. Butaye, M. Denis, J. Y. Haenni, E. Madec, and Jouy., FLaurent, A., A Battisti, P. Franco, C. Alba, A. Mammina, M. Pantosti, J. A. Monaco, E. Wagenaar, E. de Boer, M. van Duijkeren, L. Heck, C. Domínguez, M. Torres, L. B. Zarazaga, Price, and R. L. Skov. 2016. Evidence for human adaptation and foodborne transmission of livestock-associated methicillin-resistant Staphylococcus aureus. Clin. Infect. Dis. 63:1349-1352.

Merz, A., R. Stephan, and S. Johler. 2016. Staphylococcus aureus isolates from goat and sheep milk seem to be closely related and differ from isolates detected from bovine milk. Front. Microbiol. 7:319.

Monecke, S., G. Coombs, A. C. Shore, D. C. Coleman, P. Akpala, M. Borg, H. Chow, M. Ip, L. Jatzwauk, D. Jonas, K. Kadlec, A. Kearns, F. Laurent, F. G. O'Brien, J. Pearson, A. Ruppelt, S. Schwarz, E. Scicluna, P. Slickers, H.-l. Tan, S. Weber, and R. Ehricht. 2011. A field guide to pandemic, epidemic and sporadic clones of methicillin-resistant Staphylococcus aureus. PLoS One 6:e17936

Mørk, T., B. Kvitle, T. Mathisen, and H. J. Jorgensen. 2010. Bacteriological and molecular investigations of Staphylococcus aureus in dairy goats. Vet. Microbiol. 141:134-141.

Neyra, R. C., J. A. Frisancho, J. L. Rinsky, C. Resnick, K. C. Carroll, A. M. Rule, T. Ross, Y. You, L. B. Price, and E. K. Silbergeld. 2014. Multidrug-resistant and methicillin-resistant. Environ. Health Perspect. 122:471-477.

Pantosti, A. 2012. Methicillin-resistant Staphylococcus aureus associated with animals and its relevance to human health. Front. Microbiol. 3:127.

Persson, Y., and I. Olofsson. 2011. Direct and indirect measurement of somatic cell count as indicator of intramammary infection in dairy goats. Acta Vet. Scand. 53:15.

Rodríguez-Noriega, E., C. Seas, M. Guzmán-Blanco, C. Mejía, C. Alvarez, L. Bavestrello, J. Zurita, J. Labarca, C. M. Luna, M. J. Salles, and E. Gotuzzo. 2010. Evolution of methicillin resistant Staphylococcus aureus clones in Latin America. Int. J. Infect. Dis. 14:e560-e566.

Tsubakishita, S., K. Kuwahara-Arai, T. Sasaki, and K. Hiramatsu. 2010. Origin and molecular evolution of the determination of methicillin resistance staphylococci. Antimicrob. Agents Chemother. 54:4352-4359.

van Rijen, M. M., P. H. Van Keulen, and J. A. Kluytmans. 2008. Increase in a Dutch hospital of methicillin-resistant Staphylococcus aureus related to animal farming. Clin. Infect. Dis. 46:261-263.

World Health Organization. 2017. WHO publishes list of bacteria for which new antibiotics are urgently needed. Accessed Apr. 19, 2017. http://www.who.int/mediacentre/news/releases/2017/bacteria -antibiotics-needed/en/.

Zhao, Y., H. Liu, X. Zhao, Y. Gao, M. Zhang, and D. Chen. 2015. Prevalence and pathogens of subclinical mastitis in dairy goats in China. Trop. Anim. Health Prod. 47:429-435. 